\title{
Power, Professionalism, and Patient Advocacy
}

\author{
Michael B. Flynn, MD, Louisville, Kentucky
}

A shift in the balance of power from patients and physicians to managers and administrators has caused major changes in American medicine. Physicians' professional and ethical standards as well as traditional patient advocacy are challenged by the influences of entrepreneurship, commercialism, and motivations of corporate profit. As these aspects of medical practice change, the physician remains morally and legally responsible for outcomes in an environment in which the standards of practice are established by third parties whose interest does not always represent patient well-being.

In the past 2 decades, a power shift has occurred that partly explains, and is partly responsible for, the current medical climate in the United States. The balance of power in medicine in 1995 has shifted away from physicians and patients to administrators (now called CEOs [Chief Executive Officers]) and managers of everything from insurance companies to health care plans to hospital management companies. This power shift began quietly and has accelerated considerably in the last few years.

The medical profession is partly responsible for the current state of affairs due to a lack of willingness to engage the administrative and political system. The excuse offered was that our job was to take care of patients, do research, or pursue whatever interest-in other words, to wear blindersbut not become involved in the messy process of running the system. Other factors driving this change have been economics, the influence of federal, state, and local governments, and the rise and general acceptance of entrepreneurship and commercialism in medicine.

In addition to a change in the balance of power, there has been a change of purpose. This change of purpose of the medical system represents a transition from a commitment to provide high-quality care, often regardless of cost, to "efficient, cost-effective" health care. These changes were largely driven by economics, which has made the cost of health care a political issue. A manifestation of the current political significance of health care is the unsuccessful attempt at health care reform by the Clinton Administration in 1994 and the resurgence of interest in this issue by the Republican Congress.

From the Division of Surgical Oncology, Department of Surgery, University of Louisville School of Medicine, and the James Graham Brown Cancer Center, Louisville, Kentucky.

Requests for reprints should be addressed to Michael B. Flynn, MD, Department of Surgery, University of Louisville, Louisville, Kentucky 40292.

Presented at the 41st Annual Meeting of the Society of Head and Neck Surgeons, Boston, Massachusetts, May 1-3, 1995. Am J Surg. 1995; 170:407-409.
The definition of an "efficient, cost-effective" health care delivery system holds different meanings for different interests. For government, this involves the distribution of resources; whether to build roads versus treat or prevent diseases. Few votes or political contributions are generated from medical care activities, while many votes and large political contributions come from road building and many other projects that return benefit for government functionaries. For commercial interests, "tightening up" the system means reducing capital costs and operating costs. If this can be achieved without reducing the inflow of cash, a very large amount of money becomes available for commercial profit margins, stockholders' dividends, and huge salaries for CEOs and administrators. An article in the April 11, 1995, New York Times ${ }^{1}$ reveals that the 1 -year compensation (combination of salary and stock options) for CEOs of for-profit HMOs ranges from $\$ 2$ million to $\$ 15$ million.

The consequence of this power shift leaves the primary components of health care, that is, the patient and the physician, disenfranchised. In addition, a remarkable change in public ethic has occurred, allowing the predatory impact of commercial interest and entrepreneurism in health care.

This in turn has created a major ethical conflict for physicians. Traditionally advocates of patient well-being, we are now called upon to represent interests strongly motivated by commercial profit, regardless of the consequences to health care delivery.

In my view, one of the most disturbing observations of this process of change has been the general acceptance of commercial entrepreneurism in the health care system. Health insurance, supposedly created to provide personal well-being, is looked upon as an opportunity to make enormous profits. Stock reports and financial journals expound on the wisdom and cleverness of these activities with little or no evidence of public disapproval.

Today, in most parts of the country, physicians and surgeons are in the uncomfortable position of reacting to various health care plans or insurance programs that offer decreasing reimbursement for services (often significant), with little recourse but to abdicate and join or to decline to participate and be locked out of a particular program or system and suffer the financial consequences. Patients are clumped together in large insurance pools offered to the lowest bidder, often entirely unaware of the details and consequences of the choices they are asked to make. This is a gravy train that the insurance industry will ride for as long as they are allowed to. Ironically, this bond of exclusion of physicians and patients seems to be bringing patients and physicians closer and somewhat blunting the adversarial relationship that has existed for the past decade.

For the physician, this power change creates an ethical conflict as the focus shifts from the welfare of the patient to the perpetuation and financial gain of the health care system. 
Outpatient parotidectomy, thyroidectomy, and, in selected cases, neck dissection are reasonable expectations that may benefit the patient because of increased ambulation in a nonhospital environment. ${ }^{2}$ These circumstances transfer greater responsibility to the patient, physician, and family for home health care. While driven by economics, they may not result in a reduction of payor costs, but instead a redistribution within the system. The redistribution of resources from length-of-stay reductions and reduced provider reimbursement often does not flow back into the system, and, if it does, it may not be used to improve the ability to provide care or benefit patients.

I find it difficult to generate enthusiasm to support these measures in order to provide additional resources for a CEO salary or an expensive marketing campaign to attract patients to a medical activity of scientifically questionable value that is viewed as a profit center by a particular corporate entity. While a third party establishes rules regarding discharge, length of stay, et cetera, the physician is ultimately responsible morally and legally for appropriateness of medical decisions. These decisions are now made with the additional influence of economic pressure to keep "costs" to a minimum, while recognizing that hospitals affix outlandish markups onto everything provided to patients.

In this environment, the role of medical professionalism becomes critical. The physician/patient relationship-once based on a covenant in which the patient trusted the physician to do whatever is best-is being transformed into a contractual relationship in which the physician provides a service at a negotiated price. ${ }^{3}$ As this evolution of health care to a commodity occurs, the role of the medical profession also changes: physicians' ability to influence the system is decreased and their professional work values often conflict with corporate goals. This conflict produces a challenge to fundamental, traditional, medical professional standards.

Can a physician serve a patient as a trusted counselor and agent when he or she has economic ties to a profit-seeking business that regards the patient as a customer? ${ }^{3}$ This challenge also raises the question of whether a profession represents an ethical responsibility for service or an empty ideology perpetuated to retain a privileged status. ${ }^{4}$ As the status of the medical profession in general and of the surgeon in specific is declining, recognition and adherence to professional standards is clearly not an empty ideology, but represents the fundamental basis of our professional activities. Professional standards must represent a balance between the ability to provide high-quality patient care, remain a patient advocate, and function in the reality of the health care business climate of the 1990s.

The practice of providing universal high-quality care regardless of cost or outcome is, and was, irresponsible and wasteful of resources. On the other hand, exposing patients to risks in order to adhere to economic credentialling goals is professionally questionable and dangerous in the litigious climate in which we practice. Despite all the changes occurring in health care, until recently, there has been little political interest in tort reform. The current activity in Congress regarding liability reform is driven primarily by product liability concerns of business rather than by medical liability issues. As the system cranks down and decisions of patient welfare are increasingly influenced by economic factors, the physician remains caught between being responsible morally and legally for the outcomes within systems in which the practice standards have been established largely to further economic gain.

A classic example of this catch-22 for physicians was reported in the 1995 first-quarter newsletter from the Kentucky Medical Insurance Company (a physician-owned medical insurance company)..$^{5}$ A California appellate court warned that if a physician believes a patient needs more extensive care than the managed-care plan allows, then the physician has an obligation to "protest" on behalf of the patient. Failure to protest under these circumstances, according to the court, leaves the physician at least partly responsible for the outcome. A group of physicians in California began to protest when they thought the managed-care plan was too restrictive for their patients. Some of these physicians were later dropped from the managed-care network. Current California law now prevents managed care entities from penalizing physicians who challenge the plan limitations. This article predicts a storm brewing in the medical liability arena, focusing on unfavorable verdicts involving medical decisions based on financial incentives included in managed-care contracts. The predictions are that liability awards made under these circumstances will be very large.

As these choices become more difficult, a clear understanding of professional standards is increasingly important. A professional scientific society such as ours eventually will be the source of these standards. Challenges to professional standards become especially burdensome when this occurs for the purpose of furthering economic gain of a commercial interest.

One of the traditional roles of the physician was that of a patient advocate to provide advice and counsel regarding various aspects of medical care, always with the well-being of the patient as the primary consideration. As the physician/patient relationship evolves into a provider/client relationship, that fiduciary responsibility to the patient is less clear. The public expects the medical professional to remain altruistic and maintain the fundamental physician/patient trust; however, public opinion polls demonstrate a decline in confidence in the medical profession. ${ }^{6}$ Commercialism and movement away from traditional medical emphasis on altruism are felt to be the explanation for this observation.

The high public esteem of the medical profession of the past was largely due to patient advocacy and altruism. While the reality of the present and future may not allow the same degree of latitude with regard to altruism, a physician's professional integrity and commitment to patient advocacy represents one of the few break points in a system that seems intent upon devouring itself in commercialism and entrepreneurship. The social responsibility of the medical profession to provide high-quality care, maintain discipline within its ranks, and protect the public from medical hula hoops, pet rocks, and cabbage parch dolls is fundamental. ${ }^{4}$

Aside from a dinosaur howling at the moon, what does this all have to do with the Society of Head and Neck Surgeons? In the future, I believe that the role of the society will change. We will be called upon to define, more explicitly, standards of professional behavior for head and neck surgeons and oncologists. 
We will become more engaged in the socioeconomic process. This engagement has already begun with the appointment of a Joint Socioeconomic Task Force with the American Society for Head and Neck Surgery to address socioeconomic and political issues and to advise the Executive Councils of both societies as to which of these issues is most important and how these organizations should be positioning themselves and responding.

At our annual meetings, we have already begun to focus intermittently on nonclinical socioeconomic and political issues, and I predict that, for the immediate future, these matters will become an ongoing part of our agenda.

We must continue to interact with other societies and organizations with similar interests. The American Society for Head and Neck Surgery maintains an increasingly collegial and collaborative relationship. The Society of Surgical Oncology has become a very large and influential umbrella organization that represents surgical oncology. Most of us are surgical oncologists, and I feel that we need to maintain a good, but independent, relationship with the Society of Surgical Oncology and not tend to drift away-a disturbing tendency that I have observed over the past few years. The American College of Surgeons is an example of another organization with which I feel we need to maintain close contact.

Lastly, the Society of Head and Neck Surgeons must respond to the prospect of a broader role by widening its membership base to include members of other disciplines with oncologic interests. This process is also already underway as a result of recommendations, which are now being carried out at the committee level, made to the Executive Council by the Long Range Planning Committee in 1994.

In my view, the changes in American medicine are far from over. At least from our experience in Louisville, the experiment with commercial management is good for whichever organization is running the entrepreneurial system, but it has not been a good experience for the medical profession nor its patients. And it is becoming clear that the community at large is not being well served in this process. The University of Louisville Hospital has been used as a profit center by two for-profit management companies, and the Brown Cancer Center has been held hostage by this entrepreneurial process. Both of these institutions were constructed largely with community funds and contributions and, in turn, delivered by politicians to businessmen (supposedly to be run efficiently); however, the businessmen extracted enormous profit while providing minimal benefit to the institutions. Slowly, public realization of this aberrant process will, in my view, result in further change.

Hopefully, there will eventually be a return to a system in which the resources allocated for health care will be used for appropriate clinical, research, and educational purposes and not to support commercial interests, further unproductive comperition, marketing, and burdensome administrative activities.

Finally, I would like to thank the officers and members of the Society of Head and Neck Surgeons for the privilege and high honor of serving as the President for the past year. This represents one of the most significant events in my professional career.

\section{REFERENCES}

1. Freudenheim M. Penny-pinching H.M.O.s showed their generosity in executive paychecks. The New York Times. April 11, 1995:C1 (col 4), $\mathrm{C} 4(\operatorname{col} 2)$.

2. Steckler RM. Outpatient thyroidectomy: a feasibility study. Am J Surg. 1986;152:417-419.

3. Winkenwerder W, Ball JR. Transformation of American health care: the role of the medical profession. NEJM. 1988;318:317-319.

4. Levey S, Hesse DD. Bottom-line health care? NEJM. 1985;312: $644-647$.

5. Kentucky Medical Insurance Company. Liability risks in a managed care environment. Issues. (Newsletter) 1995; 1st quarter:1-2.

6. Hyman DA, Williamson JV. Setting the limits on physicians' entrepreneurship. NEIM. 1989;320:1275-1278. 